\section{Diagnostic Value of Laparoscopic Transcystic Cholangioscopy}

A 31-year-old man who had been suffering from biliary colic for three years was examined using endoscopic retrograde cholangiography, which revealed a very small defect $(2 \mathrm{~mm})$ at the duodenal end of the common bile duct (CBD) (Figure 1). Conventional ultrasonography disclosed a stone in the gallbladder. The CBD was $5 \mathrm{~mm}$ in diameter.

The patient underwent laparoseopic transcystic cholangioscopy (LTC) and laparoscopic cholecystectomy (1): After the cystic duct had been gently dilated using Maryland forceps, a cholangioscope $(3.1 \mathrm{~mm}$ in external diameter) was inserted into the CBD. More than ten polypoid lesions were detected at the duodenal end of the $\mathrm{CBD}$ (Figure 2). Biopsy of the polyps was carried out through the foreeps channel of the cholangioscope. Subsequently, laparoscopic cholecystectomy was performed using the routine methods. The patient suffered no complications from the procedure. Examination of the biopsy specimens revealed cholesterol polyps.

Reports of patients with polypoid lesions of the CBD who had neither jaundice nor dilation of the bile duct have been published previously (2). Definitive diagnosis of these lesions has often been based on pathological examination of the biopsy specimens collected through the biopsy channel of the cholangioscope after conventional open choledochotomy, or examination of surgically removed tissues (3). However, LTC can provide a definitive diagnosis of the CBD lesions without the need for choledochotomy. In cases of laparoscopic cholecystectomy, LTC is a very useful method for diagnosing bile duct diseases.

K. Ido, C. Kawamoto, K. Tamada, T. Suzuki, Y. Taniguchi, N. Isoda, K. Kimura

Dept. of Endoscopy, Jichi Medical School, Tochigi, Japan

\section{References}

1. Ido K, Kimura K, Kawamoto C, et al. Preliminary experience using laparoscopic transcystic cholangioscopy for treatment of common bile duct stones. Endoscopy 1992; 24: 749-52.

2. Shemesh E. Adenomatous polyp of the common bile duct in familial polyps coli. Isr J Med Sci 1985;21: 701-2.

3. Ezaki T, Okamura T, Yoshida Y, et al. A small polypoid lesion in the lower common bile duct: a case study. Endoscopy 1994; 26: 271 .

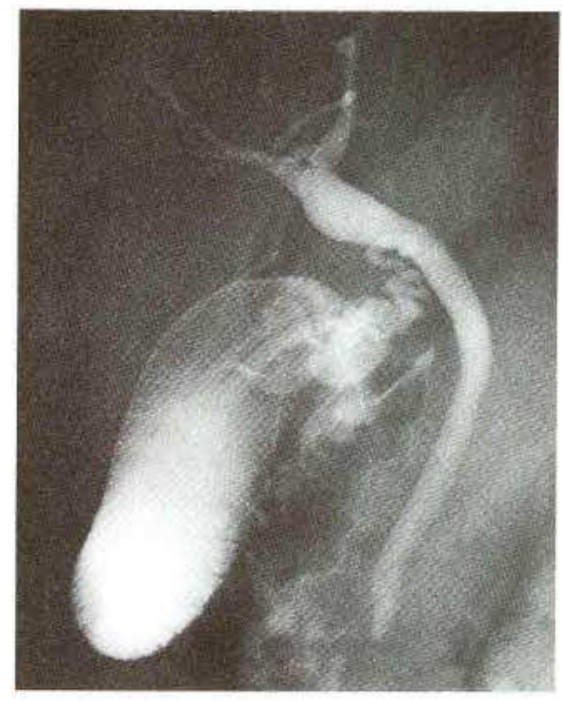

Figure 1: Endoscopic retrograde cholangiogram showing a small defect $(2 \mathrm{~mm})$ at the end of the common bile duct.

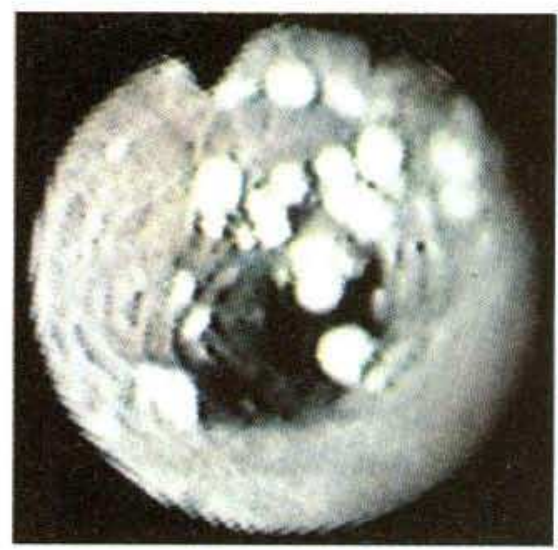

Figure 2: Cholangioscopy demonstrating small polypoid lesions at the end of the common bile duct The color of these lesions was similar to that of the surrounding tissues.
Corresponding Author

K. Kimura, M. D.

Dept. of Endoscopy

Jichi Medical School

Yakushiji

Tochigi 329-04

Japan

Fax: 81-285-40-6598 